\title{
URBAN HEAT ISLAND AND CITIES DESIGN: A Conceptual Framework of Mitigation Tools in Hot-arid Regions
}

\author{
Aboulfetouh Saad Shalaby \\ Faculty of Urban and Regional Planning, Cairo University, Egypt
}

\begin{abstract}
Urban heat island (UHI) is a climatological phenomenon which represents the difference in air temperature between urban areas, and its surrounding suburbs and undeveloped areas. $\mathrm{UHI}$ is considered as one of the major problems in the $21^{\text {st }}$ century posed to human beings as a result of high rates of urbanization. The large amount of heat generated from urban structures, as they absorb and re-radiate solar radiation, and from anthropogenic heat sources are main causes of UHI. In the ever-urbanizing Arab region, the intensifying UHI contributes to the increase of thermal discomfort of urban dwellers and, hence, the increase of their environmentally unsustainable practices. There is an utmost need, therefore, to study this phenomenon and investigate possible mitigation tools.
\end{abstract}

This paper summarizes the significance of UHI, its major characteristics and its causes. More importantly, it attempts to form a conceptual framework of countermeasures, and urban design and planning parameters which help mitigate this phenomenon. In doing so, this theoretical study capitalizes on immense literature which has addressed the issue, yet, basically from a climatological point of view. It attempts to look at the subject from an urban design and planning point of view. The study, therefore, brings together two disciplines, climatology and cities design and planning, an attempt in the field of UHI that has been rarely tackled on the Arab region. The resulting collective conceptual framework is seen in this paper as a necessary first step towards deeper investigation into urban planning and design parameters which could help reduce the impact of UHI and, hence, create better quality of life in the Arab world.

\section{Keywords}

Urban heat island, sustainable urban practices, urbanization

\section{المخذص}

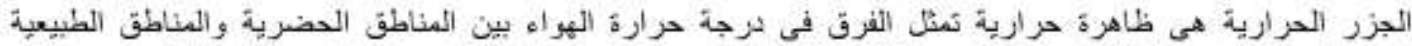

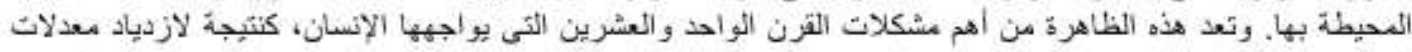

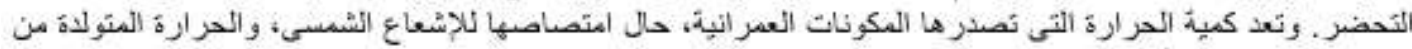

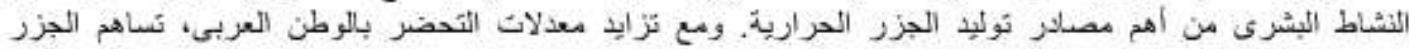

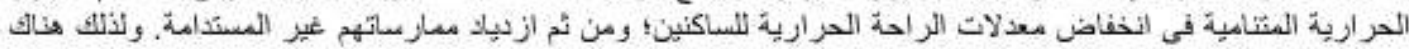

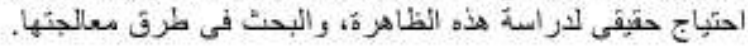

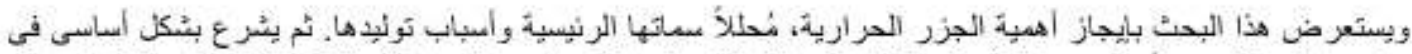

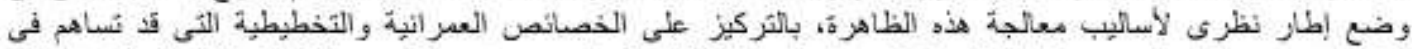

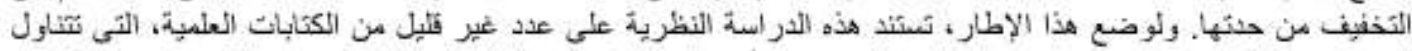

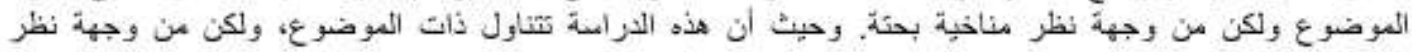

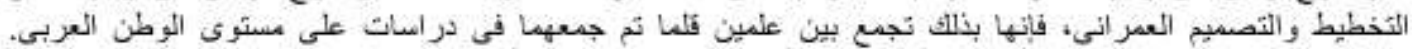

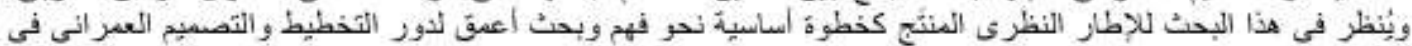

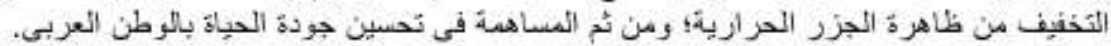




\section{INTRODUCTION}

The Urban Heat Island (UHI) is a common phenomenon whereby urban/developed areas experience higher air temperatures (in and above) than undeveloped/rural surroundings (USEPA, 2009d; Pearlmutter, 2000; DPP, 2008; Memon et al, 2008; USEPA, 2009e). This temperature excess of cities that is caused by urbanization 'is a well-known and thoroughly researched phenomenon of urban climatology' (Bottyan et al, 2005, 405). As urban areas develop, changes occur in their landscape. Buildings, roads, and other infrastructure replace open land and vegetation. These urban changes, along with waste heat generated by energy usage (Wikipedia, 2009), cause urban regions to become warmer than their rural/undeveloped surroundings, forming an "island" of higher temperatures in the landscape (USEPA, 2009b). The annual mean air temperature of a city with one million or more people can be 1 to $3^{\circ} \mathrm{C}$ warmer than its surroundings, and on a clear, calm night, this temperature difference can be as much as $12^{\circ} \mathrm{C}$ (USEPA, 2009d). Even smaller cities and towns will produce heat islands, though the effect often decreases as city size decreases (USEPA, 2009d). 'This concept, however, covers a range of diversified ideas that include the temperature difference between the well developed urban area and least developed area or between two different built-up areas' (Memon et al, 2008, 122).

$\mathrm{UHI}$ is considered as one of the major problems in the 21st century posed to human beings as a result of high rates of urbanization. The trend of urbanization is both accelerating and irreversible. $60 \%$ of world population is expected to live in cities by the year 2030 (IRIN, 2011). While developed countries will remain far more urbanized than the developing world, urban growth in developing countries, to which the Arab world belongs, is more rapid and, in absolute numbers, much greater (Golden, 2004). UN-HABITAT forecasts that, 'over the next two decades, 90 percent of population growth in developing countries will be urban' (IRIN, 2011, 1). Further, 280 million people live in at least 25 mega-cities across the world, three-quarters of which are located in the developing world. This figure is expected to rise to 350 million by 2015 (IRIN, 2011). This unprecedented explosion of municipal communities poses unique challenges to city planners in terms of the accentuation of UHI phenomenon (Golden, 2004). There is an utmost need, therefore, to study this phenomenon and investigate possible mitigation tools.

This paper summarizes the significance of $\mathrm{UHI}$, its major characteristics and its causes. More importantly, it attempts to form a conceptual framework of countermeasures and urban design and planning parameters which help mitigate this phenomenon. Multiple literatures have highlighted the under-researched potential role of urban design and planning parameters, the main focus of this paper, and the utmost need for more research on their role in mitigating UHI. Ooka (2007) admits that 'vast wealth of urban climate knowledge has not been sufficiently applied to urban design and planning' (1928). Memon et al (2008) suggests that the future research should be focused on design and planning parameters -seen as the main reason of heat inputs- for reducing the effects of urban heat island and ultimately living in a better environment. They consider these parameters to be 
complex but important and need 'more research and efforts for achieving promising mitigation benefits' (126). In tune, USEPA (2009d) names urban geometry as a key parameter worth of future research as the height and spacing of buildings significantly affect the amount of radiation received and emitted by urban infrastructure. And, others urge planners, specifically those in arid regions, to help govern the underlying structure of cities in such a way that could enhance the thermal performance of new development (Stone and Norman, 2006), and support the growth of the new and existing arid urban centers, commonly found in the Arab world, in a sustainable manner (Golden, 2004).

To form a conceptual framework of countermeasures and urban design and planning parameters, the study capitalizes on immense literature which has addressed the issue. It is, therefore, a theoretical study in that it involves the review, critique and integration of existing theorylconcepts, and relies entirely on existing literature as a resource (Blaike, 2000). This existing theory however has mostly addressed the issue from a climatological point of view. Yet, the study attempts to look at the subject from an urban design and planning point of view. The resulting collective conceptual framework is seen in this paper to be a necessary first step towards deeper investigation into urban planning and design parameters which could help reduce the impact of UHI and, hence, create better quality of life in the Arab world.

The paper is organized in three sections. The first shows the UHI significance, presents its types and characteristics, and discusses how the phenomenon is generated. The second sets out to construct a conceptual framework of countermeasures, and urban design and planning parameters which could help mitigate this phenomenon in the Arab world. The third presents conclusions and avenues for future research.

\section{URBAN HEAT ISLAND'S SIGNIFICANCE, TYPES, CHARACTERISTICS AND GENERATION}

This part shows the UHI significance; presents the different types of UHIs highlighting the type which is commonly most-observed, the canopy layer UHI; delineates general characteristics of the phenomenon; and discusses how it is generated, highlighting the significant role played by urban geometry.

\subsection{Significance of UHI}

'It might be because the possible benefits of reducing UHI are enormous, the research community has carried out vast research work in this field and therefore large amount of literature are available' (Memon et al, 2008, 120). Elevated temperatures from urban heat islands, particularly during the summer, can affect a community's environment and quality of life. While some impacts may be beneficial, such as lengthening the plant-growing season, the majority of them are negative (USEPA, 2011a). These impacts include: 


\subsubsection{Increased energy consumption}

Elevated summertime temperatures in cities, especially those in comparatively hot climates, increase energy demand for cooling (USEPA, 2009e, 2011a; Wikipedia, 2009; Akbari, 2006) in residential and commercial buildings (USEPA, 2009a).

\subsubsection{Elevated emissions of air pollutants and greenhouse gases}

As urban heat islands raise demand for electrical energy in summer, companies that supply electricity typically rely on fossil fuel power plants to meet much of this demand, which in turn leads to an increase in air pollutant and greenhouse gas emissions $^{1}$ (USEPA, 2009e, 2011a; USEPA, 2009a). Nitrogen oxides and volatile organic matters along with other air pollutants chemically react with sunlight forming smog which one of its constituents is harmful ground-level ozone. Higher temperatures in urban areas, accentuated by UHIs, often speed the formation of smog (Sarrat et al, 2006; USEPA, 2009a, 2009e; Akbari, 2006).

\subsubsection{Compromised Human Health and Comfort}

UHIs have the potential to directly (Wikipedia, 2009) and indirectly (USEPA, 2009e) influence the health and welfare of urban residents. Increased daytime temperatures, reduced nighttime cooling (as direct products of UHI), and higher air pollution levels (as an indirect product of UHI) can affect human health ${ }^{3}$ by contributing to general discomfort ${ }^{4}$, respiratory difficulties, heat cramps and exhaustion, non-fatal heat stroke ( USEPA, 2011a), heat-related illness and even mortality ${ }^{5}$ (USEPA, 2009e; Memon et al, 2008), and stress and anti-social behaviors (Pherson, 2011), most apparent, for example, in hot and crowded Egyptian summer days.

\subsubsection{Elevated water demand \& impaired water quality}

Urban heat islands increase outdoor demand for water, particularly in desert cities ${ }^{6}$. Further, UHIs affect water use indirectly by increasing energy use, because

\footnotetext{
${ }^{1}$ Examples on such emissions are carbon dioxide (CO2), sulfur dioxide, carbon monoxide, nitrogen oxides, and particulate matter.

${ }^{2}$ It is reported that for every 1/2 Fahrenheit above 70 there is $5 \%$ increase in polluting smog (Gardiner and Heller, 2008).

${ }^{3}$ Those at significant risk from extreme heat and ozone exposure include the elderly, children, and individuals with pre-existing respiratory disease (USEPA, 2009e).

${ }^{4}$ With its extreme summer temperatures, Phoenix, for example, poses unique challenges to pedestrian comfort. High daytime and evening temperatures combine to raise the temperature of the built environment with little opportunity to lower the heat during the evening hours, hence the use of air conditioning which consumes energy and adds heat to the outdoor environment (DPP, 2008).

${ }^{5}$ UHIs can potentially increase the magnitude and duration of heat waves within cities. Research has found that the mortality rate during a heat wave increases exponentially with the maximum temperature, an effect that is exacerbated by the UHI. The nighttime effect of UHIs can be particularly harmful during a heat wave, as it deprives urban residents of the cool relief found in rural areas during the night (Wikipedia, 2009).

${ }^{6}$ In Phoenix, for example, two-thirds of all residential water use is for outdoor purposes, and, thus, sensitive to climate. In addition, 'the city's 322,828 single-family housing units in 2005 (U.S. Census Bureau, 2007) used an additional 94 million gallons of water in the month of June as a result of the UHI' (Guhathakurta and Gober, 2007, 327).
} 
thermoelectric power generation requires water for cooling (Guhathakurta and Gober, 2007). UHIs also impair water quality. Hot pavement and rooftop surfaces transfer their excess heat to storm water, which then drains into storm sewers and raises water temperatures as it is released into streams (Wikipedia, 2009). The increase in water temperature negatively affects all aspects of aquatic life ${ }^{7}$ (USEPA, 2011a).

\subsubsection{Effect on meteorology and climate}

Aside from the obvious effect on temperature and air quality (Wilby, 2008), UHIs can produce secondary effects on local meteorology, including the altering of local wind patterns ${ }^{8}$, the development of clouds and fog, the humidity, and the rates of precipitation ${ }^{9}$.

\subsubsection{Relation to global warming}

In common usage, "global warming" often refers to the warming that can occur as a result of increased emissions of greenhouse gases from human activities (USEPA, 2009d). While some scholars believe that global warming is very unlikely to be influenced significantly by increasing urbanization (Wikipedia, 2009) many others believe that, as more than $50 \%$ of the human population lives in cities, urbanization has become an important contributor to global warming through $\mathrm{UHI}^{10}$ (USEPA, 2011a; Chen et al, 2006). 'Thus, advancing measures to mitigate urban heat islands also helps to address global climate change' (USEPA, 2009d, 6).

\subsection{Urban Heat Island Types}

Heat islands occur on the surface and in the atmosphere, distinguishing therefore between two types, the surface and the atmospheric. While higher surface temperature in urban areas compared to that of nearby rural surroundings define surface UHI, warmer air in urban areas compared to cooler air in nearby rural surroundings defines atmospheric urban heat islands (USEPA, 2009d).

Both types are typically present day and night. Yet, surface UHI tends to be strongest during the day when the sun is shining. In contrast, atmospheric urban heat island is often weak during the late morning and throughout the day, and becomes more pronounced after sunset due to the slow release of heat from urban structures and surfaces (USEPA, 2009b). Also, atmospheric heat islands vary much less in intensity than surface heat islands (USEPA, 2009d).

\footnotetext{
${ }^{7}$ Rapid temperature changes in aquatic ecosystems resulting from warm storm water runoff can be particularly stressful, even fatal to aquatic life (USEPA, 2011a).

${ }^{8}$ The combinations of mixed height and dimensions of buildings impact air flow above and within urban environments (Golden, 2004).

${ }^{9}$ NASA researchers have confirmed that urban heat-islands create more summer rain over and downwind of major cities. Rising warm air, which destabilizes and changes the way air circulates around cities, may help produce clouds that result in more rainfall around urban areas (NASA, 2002).

to Highlighting a mutual relationship between UHIs and global warming, it is also argued that global warming may, in turn, increase frequency of temperature extremes enhanced by the UHI effect (Golden, 2004).
} 
Further, experts often divide atmospheric heat islands into two different types:

1. Canopy layer urban heat islands: which exist in the layer of air where people live, from the ground to below the tops of trees and roofs.

2. Boundary layer urban heat islands: which start from the rooftop and treetop level and extend up to the point where urban landscapes no longer influence the atmosphere. This region typically extends no more than one mile from the surface (USEPA, 2009d).

Canopy layer urban heat islands are the most commonly observed of the two types and are often the ones referred to in discussions of urban heat islands (USEPA, 2009d) as well as in this paper. It is the layer 'in which the engineered environment has the most pronounced effect, as the airflow and energy exchanges are controlled by microscale, site-specific characteristics ${ }^{11}$ (Golden, 2004, 328).

\subsection{UHI Characteristics}

No constant rule applies to diurnal, weekly or seasonal variation of UHI. Urban heat islands like most ecological phenomenon are not a singularity (Vasishth, 2006). 'It seems that depending on the area and its energy use the term could be significant or negligible and it could have varying diurnal, seasonal or even weekly trends' (Memon et al, 2008, 124). Yet, some general characteristics could be identified as follows:

1. Urban heat islands can occur throughout the year (Guhathakurta and Gober, 2007).

2. They are often higher in summer than winter (Wikipedia, 2009), due to higher solar radiation, lower wind, over-used cooling systems, and lack of rain and hence lack of evapotranspiration ${ }^{12}$. In addition, UHIs reduce need for heating in winter but require more cooling in summer.

3. They are usually greatest after sunset or overnight, and smallest, sometimes even negative, after sunrise or during the morning or early afternoon (Golden, 2004; USEPA, 2011a; Souza et al, 2003; Wikipedia, 2009; Memon et al, 2008). They reach their maximum intensity usually a few hours after sunset (USEPA, 2009d).

4. UHIs greatest development is highly linked to calm air and cloudless sky (Wikipedia, 2009; Memon et al, 2008). Heavy cloud cover blocks solar radiation, reducing daytime warming in cities. Strong winds increase atmospheric mixing, lowering the urban-rural temperature difference (USEPA, 2009d). In contrast, when wind speed is low and the sky is cloudless, radiative cooling is more dominant (Wikipedia, 2009), allowing UHI to develop.

5. Their effect is most pronounced in highly developed areas (DPP, 2008).

${ }^{11}$ 'By contrast, the urban boundary layer above the roof level is affected by the land-use zones and mesoscale phenomenon and controlled by processes operating at larger spatial and temporal scales' (Golden, 2004, 328).

${ }^{12}$ The process of transferring moisture from the earth to the atmosphere by evaporation of water and transpiration from plants (Dictionary.com, 2011) 
6. They develop rapidly with urbanization (Chen et al, 2006) and their effect often increases as city size increases (USEPA, 2009d; Hedquist et al, 2009).

7. Their effect is typically most intense in the urban core and less severe on the urban periphery (Guhathakurta and Gober, 2007).

8. Variation in the UHI effect across an urban area is caused by the amount of sun-warmed urban surface exposed to the cold night sky, and, thus, related to variations in land use, building materials and heights, street geometry, and spacing between buildings, among other natural and manmade factors (Guhathakurta and Gober, 2007). Additionally, but to a lesser extent, variation in the $\mathrm{UHI}$ is caused by the introduction of anthropogenic heat which comes from heat being released from engines and mechanical cooling equipments (DPP, 2008). That explains the occasional decrease in UHI intensity during weekends as cities are relatively dormant with lower anthropogenic heat released.

\subsection{Generation of Urban Heat Island}

$\mathrm{UHI}$ is the mutual response of many factors, as implicitly indicated in the previous section, which could broadly be categorized as controllable and uncontrollable factors $^{13}$. The controllable factors are mostly design and planning related which could be humanly controlled to some extent while the uncontrollable factors are environment and nature related which are normally beyond our control (Memon et al, 2008). The following shows how these factors together interact to form Urban Heat Islands.

Rapid urbanization is creating extreme changes in land use that result in unintended environmental consequences (Bottyan et al, 2005). In urban areas, buildings and paved surfaces have gradually replaced preexisting natural landscapes (Golden, 2004). Throughout the daytime, particularly when the skies are free of clouds, these urban surfaces are warmed by the absorption of solar radiation. Surfaces in urban areas tend to warm faster than those of surrounding rural/undeveloped areas. By virtue of their high heat capacities and lower albedo ${ }^{14}$, these urban surfaces act as a giant reservoir of heat energy. Loss of evapotranspiration, due to reduced vegetation, a typical urban property ${ }^{15}$, and, hence, reduced latent heat transfer, compounds the situation (Hedquist et al, 2009). However, as is often the case with

${ }_{13}$ The controllable and uncontrollable factors could further be categorized as the temporary effect variables, such as air speed and cloud cover, permanent effect variables such as green areas, building materials, and sky view factor, and cyclic effect variables such as solar radiations and anthropogenic heat sources (Memon et al, 2008).

14 The ratio of the light reflected by any part of the earth's surface or atmosphere to that received by it (Dictionary.com, 2011).

${ }^{15}$ Urban areas are characterized by dry, impervious surfaces, such as conventional roofs, walls, sidewalks, roads, and parking lots. As cities develop, more vegetation is lost, and more surfaces are paved or covered with buildings. The change in ground cover results in less moisture to keep urban areas cool. Built up areas evaporate less water, which contributes to elevated surface and air temperatures (Akbari, 2006; USEPA, 2009d). 
daytime heating, this warming also has the effect of generating convective winds ${ }^{16}$ within the urban boundary layer. It is theorized that, due to the atmospheric mixing that results, the air temperature $\mathrm{UHI}$ is generally minimal or nonexistent during the day, though the surface temperatures can reach extremely high levels (Wikipedia, 2009).

At night, however, the situation reverses. The absence of solar heating causes the atmospheric convection to decrease, and the urban boundary layer begins to stabilize. If enough stabilization occurs, supported by urban geometry which hinders air flows due to urban roughness and decreases radiative characteristics due to low sky view factor ${ }^{17}$ (Golden, 2004), an inversion layer is formed. This traps the urban air near the surface, and allows it to heat from the still-warm urban surfaces, forming the nighttime air temperature UHI (Wikipedia, 2009). This could build up day after day till it is broken by strong/rainy winds to start over.

The scenario slightly differs in hot arid regions. A hot-arid climate has a strong sunshine with a large portion of direct radiation where cloud cover is generally less (Rosenlund, 2000). The environment heats up scoring high temperatures, especially with the lack of evapotranspiration due to reduced access of soil moisture (Golden, 2004). These conditions reach their maximum in open bare deserts. Urban/developed areas, however, due to shade and introduction of moisture (if development introduces grass lawns and other irrigated vegetation) (USEPA, 2009b), are characterized by a relative daytime oasis effect (Golden, 2004). At nighttime, due to clear night skies, the potential for radiative cooling is high, and hence great differences between day and night temperatures occur (Rosenlund, 2000). Again, this reaches its maximum in open bare deserts.

But, in urban areas, lack of wind, low sky view factor and temperature inversion impair radiative cooling, and hence generate a very strong hysteresis lag effect at night (Golden, 2004), resulting in high UHI magnitudes particular to desert regions ${ }^{18}$ (Guhathakurta and Gober, 2007) (Figure "1"). This happens even in small desert cities of 30,000 people (Hedquist et al, 2009).

The following sections discuss in more details the controllable and uncontrollable factors forming UHIs.

${ }^{16}$ Convection describes the transfer of sensible heat between the surface and air when there is a difference in temperature between them. High urban surface temperatures warm the air above, which then circulates upwards via convection (USEPA, 2009d).

17 The Sky View Factor (SVF) 'represents an estimation of the visible area of the sky from an earth viewpoint, being defined as the ratio between the total amount of radiation received from a plan surface and that available from the whole radiant environment. It is thus a dimensionless parameterization of the quantity of visible sky at a location. In this way the sky area results from the limits of urban canyons generated by the tri-dimensional characteristics of urban elements and their mutual relationships' (Souza et al, 2003, 1228).

${ }^{18}$ Previous research in Phoenix has shown that the UHI magnitude can be as much as $10-11$ oC three to five hours after sunset (Hedquist et al, 2009). 
Figure (1) Daytime oasis effect and night-time hysteresis lag effect in deserts

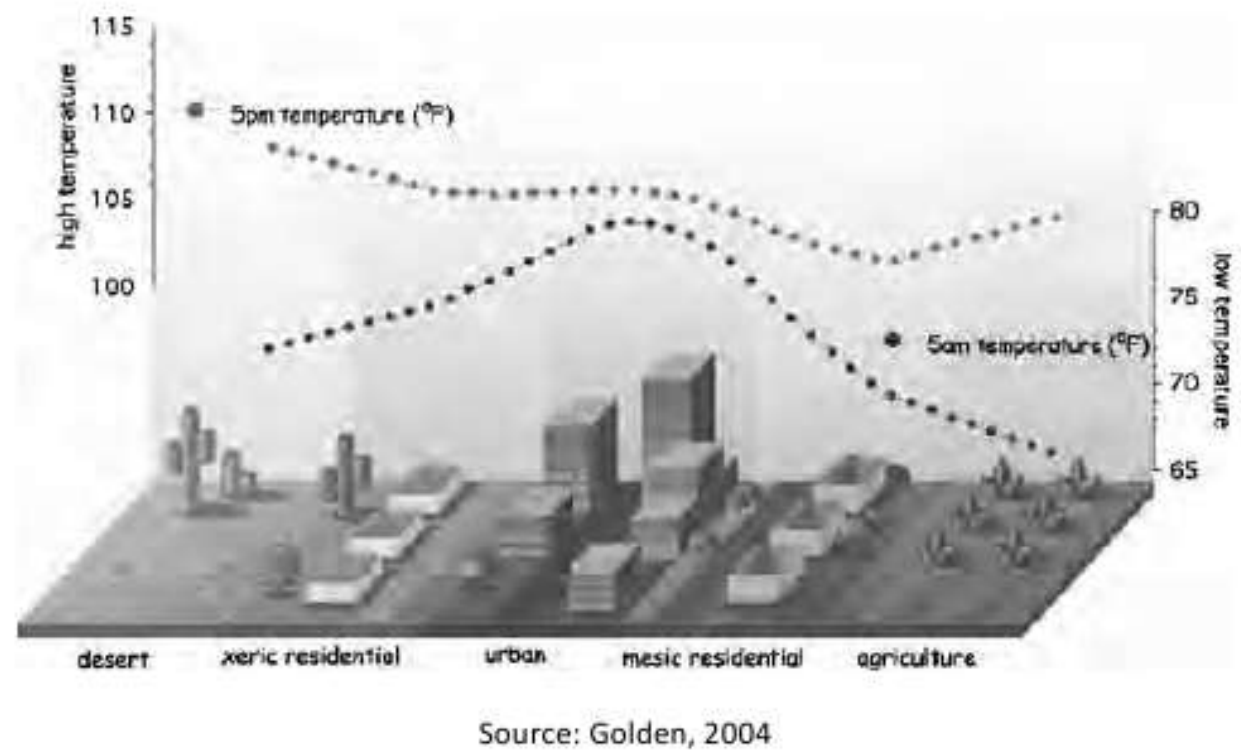

\subsubsection{Controllable causes}

Part of the heat generated by solar radiation heats up the environment directly and the rest are consumed by the urban structures and surfaces which in turn heat up the environment indirectly (Hedquist et al, 2009). However, as the direct solar heating will affect both urban and rural areas simultaneously and equally, the indirect solar heating (ISH) is a main cause of UHI. It depends on building geometry and surface thermal properties that have been shown to have the largest effect on the magnitude of the UHI (Hedquist et al, 2009; Memon et al, 2008).

Research shows higher density urban settings/compact urban geometry to result in more severe UHI effects (Bottyan et al, 2005; Hedquist et al, 2009; Pearlmutter, 2000; Guhathakurta and Gober, 2007) as it changes net radiation (Golden, 2004). Researchers often focus on an aspect of urban geometry called urban canyons, which can be illustrated by a relatively narrow street lined by tall buildings (USEPA, 2009d). The tall buildings within many urban areas shade surfaces but at the same time provide multiple surfaces for the reflection and absorption of sunlight shortwave $^{19}$ radiation, which further lower the city's overall albedo-the net reflectance from surface albedo plus urban geometry (Memon et al, 2008; USEPA, 2009d) and increase the efficiency with which urban areas are heated. The heat absorbed by these buildings at daytime is then released slowly at night time (Jusuf et al, 2007). Due to the dense infrastructure in some developed areas that have low sky view factors $^{20}$, urban areas cannot easily release long-wave radiation to the cooler, open

19 Short-wave radiation is ultraviolet, visible light, and near-infrared radiation from the sun that reaches the Earth. This energy is a key driver of urban heat islands (USEPA, 2009d).

20 The effects of urban geometry on urban heat islands are often described through the "sky view factor" (SVF) (USEPA, 2009d). The less a surface has visibility to the sky, the slower its cooling ability. Therefore, sky view factor (SVF) is one of the main heat island causes (Souza et al, 2003; Guhathakurta and Gober, 2007). the effects of urban geometry on urban heat islands are often described through the "sky view factor" (SVF), (12) (USEPA, 2009d) 
sky, and this heat trapped contributes to the urban heat island (USEPA, 2009d). This is called the "canyon effect" (Wikipedia, 2009; USEPA, 2009d). Another effect of buildings is the blocking of wind (Golden, 2004; Wikipedia, 2009). High roughness of buildings distribution reduces the amount of convective heat removal and transfer by wind (Memon et al, 2008; Hedquist et al, 2009; Wikipedia, 2009; USEPA, 2009d). ${ }^{21}$

Properties of urban materials, in particular solar reflectance, thermal emissivity, and heat capacity, also influence urban heat island, as they determine how the sun's energy is reflected, emitted, and absorbed (USEPA, 2009d). The larger volume of asphalt, brick, concrete, steel, stone and other materials gives urban areas a much higher thermal storage capacity than natural materials such as dry soil and sand (Guhathakurta and Gober, 2007). These darker ${ }^{22}$ and dense urban surfaces, compared to vegetation and other natural ground cover, reflect less radiation back to the atmosphere (USEPA, 2009d). One result is that large amounts of energy are stored in the urban canopy by these dense materials during the day and released after sunset ${ }^{23}$ (Golden, 2004, 327). Although solar reflectance is the main determinant of a material's surface temperature, thermal emittance, or emissivity, also plays a role as a low emittance surface reaches thermal equilibrium at higher temperatures which help store more heat (USEPA, 2009d; Memon et al, 2008).

Other controllable factors which influence UHI are city size and population density. The UHI has been reported to potentially be positively correlated with the city population density (Memon et al, 2008; Guhathakurta and Gober, 2007), and urban size (Chen et al, 2006; Song, 2005; Stone and Norman, 2006). The bigger and denser a city, the more intense is its UHI. Anthropogenic heat generated by cars, air conditioners, industrial facilities, and a variety of other manmade sources is an important cause of UHI (Guhathakurta and Gober, 2007). It heats up the environment instantly and directly (Memon et al, 2008), and contributes to the urban energy budget (Wikipedia, 2009), particularly in the winter (USEPA, 2009d), as it is accounted for almost all of the sensible heat flux in urban areas (Kato and Yamaguchi, 2005). High levels of pollution in urban areas can also increase the UHI, as many forms of pollution change the radiative properties of the atmosphere ${ }^{24}$ (Wikipedia, 2009).

21 The processes which cause overheating within such street canyons have been found to be prominent during the daytime as well (Pearlmutter, 2000).

22 Five percent of solar energy is in the UV spectrum, 43 percent is visible light, in colors ranging from violet to red; and the remaining 52 percent is infrared, felt as heat. Much of the sun's energy is, thus, found in the visible wavelengths; thus, solar reflectance is correlated with a material's color (USEPA, 2009d).

23 In a UHI study conducted on London, surface albedo was found to be the most critical variable that determines daytime and nocturnal change in outdoor air temperature (Kolokotroni and Giridharan, 2008).

${ }^{24}$ Air-born pollutants accumulate in the urban canopy layer (DPP, 2008). It is believed that these pollutants, in particular aerosols that are abundant over polluted urban areas, can absorb and re-radiate long wave radiation and inhibit the corresponding radiative surface cooling producing a pseudo-greenhouse effect, which are responsible for causing UHI (Memon et al, 2008). 
Having in mind the different mixes and degrees of these controllable factors associated with different land uses, land use types were found to differently affect UHI intensity (Guhathakurta and Gober, 2007; Chen et al, 2006). A study made on Singapore ranked Land use types according to their influence on ambient temperature. In the daytime, the order of surface temperature in different land use types is industrial, commercial, airport, residential, and park respectively. However, during the night time, the order is commercial, residential, park, industrial, and airport $^{25}$ (Jusuf et al, 2007).

Another study conducted on Bundang area, China, shows that residential and commercial areas were responsible for increases in the total average temperature of the ground surface, followed by transportation facilities (Song, 2005). Conclusively, research shows that 'land use planning becomes critical in determining the environment quality' (Jusuf et al, 2007, 232).

\subsubsection{Uncontrollable causes}

Climate and topography, which are in part determined by a city's geographic location, influence urban heat island formation (Wilby, 2008). Solar radiation, cloud cover and wind speed play a significant role in determining the intensity of UHI, as discussed earlier. Humidity would be another important impact factor to UHI intensity as it prevents potential evapotranspiration and hinders radiative cooling, and the UHI would be weaker from this perspective when the study area is arid (Chen et al, 2006). Examples for the influence of topography include the potential of large bodies of water to moderate temperatures and generate winds that convect heat away from cities. Nearby mountain ranges can either block wind from reaching a city, or create wind patterns that pass through a city. Local terrain has a greater significance for heat island formation when larger-scale effects, such as prevailing wind patterns, are relatively weak (USEPA, 2009d).

To conclude, the UHI is caused by uncontrollable and controllable factors. The uncontrollable factors are basically climate and topography. The controllable factors are directly and indirectly related to planning and design issues, and include urban geometry, surface thermal properties, city size, population density, anthropogenic heat sources, pollution levels, and land use types. Among these factors, urban geometry and surface thermal properties, responsible for $\mathrm{ISH}$, and anthropogenic heat are the main causes of UHI respectively. The heat re-radiated by urban structures plays the most important role which should be given first priority when formulating UHI mitigation tools (Memon et al, 2008).

${ }^{25}$ During daytime, the industrial area has a very high surface temperature due to a large open concrete surface area and high-dense metal and concrete roof buildings. In the airport area, high surface temperature is mainly due to a large open concrete area. In residential area, the mixed upper medium and medium temperatures are mainly due to the presence of greenery, while in the CBD, they are mainly due to the shading from high-rise buildings. At night time, the condition turns the other way round. Industrial area and airport seem to have a lower ambient temperature as compared with CBD and residential area because of their lower thermal capacity (Jusuf et al, 2007). 


\section{CONCEPTUAL FRAMEWORK OF MITIGATION TOOLS}

This section collects and examines different UHI mitigation tools discussed in literature available. A construct of an integrated conceptual framework is the climax of this examination. This framework is directed mainly to subtropical hot arid regions which constitute a significant portion of the Arab world. The section, also, helps identify gaps in knowledge, opening, therefore, avenues for future research.

Despite the fact that this study focuses on how to mitigate UHI, which is basically a nocturnal phenomenon, this cannot be tackled apart from the consequences of this mitigation on the daytime comfort level. This is specifically significant when addressing subtropical hot arid regions, most characterized by intense solar radiation. Therefore, escaping the severe daytime climatic conditions has to be considered along with the attempt to alleviate UHI. This consideration ranges from striking a balance between daytime and nighttime comfort levels (DPP, 2008) to even the mere acceptance of an argument that 'an increase in temperature would probably be welcomed at night if concomitantly extreme temperature stress during the day is alleviated' (57) making use of the fact that night-time temperatures are usually significantly lower than day-time temperatures in hot arid areas (Ratti et al, 2003). This range of considerations is in tune with the fact that hot arid areas are not a singularity. Building on this, this section tends to refrain from assigning exact values to design/planning parameters discussed. And, if it inescapably does, that would be subject to further examination in order to reach case-specific parameters.

Finally, while this section attempts to encapsulate accumulated wisdom for inhabiting the desert (Pearlmutter, 2000), it realizes the fact that 'contemporary conditions such as tall buildings, UHI, new building materials and air pollution present new conditions that require a reconsideration of the historical model' (DPP, 2008, 4-5).

\subsection{Smart Compact Urban Geometry}

A shallow compact urban form functions well in hot arid climates (Ratti et al, 2003; Shalaby, 1995). It protects pedestrians from direct solar radiation (Rosenlund, 2000) and over-heated surrounding air (USEPA, 2009e; Pearlmutter, 2000; Stone and Norman, 2006) at daytime. During nighttime, due to rapid nocturnal cooling (DPP, 2008) pertained to a shallow form, the resulting UHI is seen to be relatively insignificant (Ratti et al, 2003) to the extent that it is called 'a relative "cool island," in sharp contrast to what is often emphasized in non-arid cities ${ }^{\prime 26}$ (Pearlmutter, 2000, 6). Yet, the deeper the compact form - a common practice in contemporary cities, the more intense is the UHI generated, as the sky view factor gets lower, and, hence, much of the heat absorbed is not released to the atmosphere during evening hours (DPP, 2008).

${ }^{25}$ This is what makes Gardiner and Heller (2008) argue that UHI has been mistakenly used to advocate low-density dispersed urban growth. 
In addition, a uniform compact form with narrow winding street pattern provides shelter from harmful hot sand-laden wind, directing it up and over the urban canopy layer (DPP, 2008; Shalaby, 1995). Yet, it contributes to the increase of UHI intensity as it prevents air flow from taking heat and pollutants outside the canopy layer ${ }^{27}$. Also, small amounts of airflow at daytime, potentially hindered in this case, is crucial as they promote evaporation, can remove excess surface heat through convective flows, and are a major factor to perceived levels of comfort (DPP, 2008).

So, what is the sort of contemporary compact geometry that could be smart, balancing daytime comfort and $\mathrm{UHI}$ in a hot desert environment?

\subsubsection{Street canyon ratio and orientation}

Using computer simulation, a strong correlation between canyon orientations and proportions, and the amount of human comfort within these canyons is confirmed (Hedquist et al, 2009). In relation to protection from solar radiation, it is found that a canyon with north-south orientation is performing better than a canyon with east-west orientation, both with a width-height proportion of 1:3 (DPP, 2008). It is also found that a $1: 3$ proportion has to be given to street canyon along the northsouth axis in order to maintain a better pedestrian thermal comfort. But for street canyons along west-east axis, there is no significant difference in thermal performance between the $1: 2$ and $1: 3$ proportions (Figure " 2 ").

Figure (2) Street canyon proportions
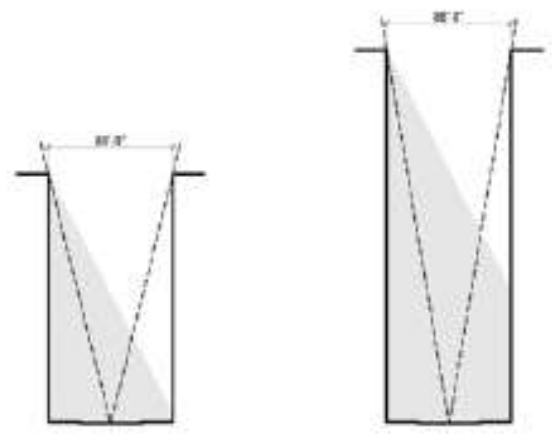

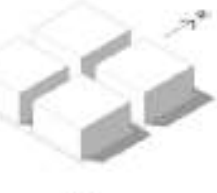

$1: 2$

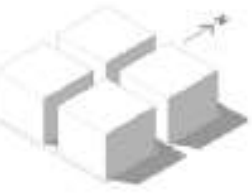

$1: 3$
Source: DPP, 2008

Therefore, a street canyon proportion of $1: 2$ is recommended along west-east axis to balance thermal comfort and UHI, providing a relatively cool pedestrian environment during the day while permitting an acceptable amount of heat release during evening hours ${ }^{28}$ (DPP, 2008). For further enhancement of the performance of these canyons, they could be covered or lined by arcades, adding more shade (Rosenlund, 2000).

In relation to wind generation, a street canyon would allow air flow if the prevailing preferable wind is parallel to its axis, creating cold air corridors (Song, 2005). The

${ }^{27}$ Reductions in $\mathrm{UHI}$ of $0.21{ }^{\circ} \mathrm{C}$ for every increase in wind speed of 1 kilometer per hour have been noted in Melbourne Australia when wind speeds exceed 8 kilometers per hour (DPP, 2008).

${ }^{28}$ Studies of traditional cities in semitropical regions show the prevalence of effective street canyon proportions of 1:3 (width to height) regardless of its orientation (DPP, 2008). 
wind gets even stronger in a deeper canyon than in a shallower one (Pearlmutter, 2000). Using computer simulation, studies indicate that a $1: 1$ street canyon proportion is at the lower end of the threshold for effective wind ventilation with the ideal height to width proportion being 1.54 (DPP, 2008). Further, increased turbulence and vertical flow, to flush out not only heat but also particulate, is produced when 'the wind is permitted to flow through open channels roughened by the removal of significant portions of the street wall volume, including entire blocks' (DPP, 2008, 4-11). Yet, further research is needed to study the impact of these UHI mitigation tools on daytime comfort zone in relation to hot sand laden winds. In addition, having assigned different proportions to street canyons when performing different functions (shade and airflow creation), further research is needed to study how these differences can be resolved in a specific hot arid environment.

To balance thermal comfort and UHI in high rise commercial and residential districts, blocks are divided into building bases and towers (DPP, 2008). A relatively compact form is applied to building bases covering a higher percentage of land lots to maximize ground-level shade, while towers are relatively dispersed covering lower percentage of land lots to enhance air flow within the urban canopy and hence alleviate UHI. Additional air turbulence is produced by placing these towers diagonally at the corners of the blocks (DPP, 2008) (Figure " 3 "). In this case, the same street canyon proportions suggested earlier for shade or air flow purposes apply but as an average measured over entire blocks.

Figure (3): Proposed form for blocks bases and towers
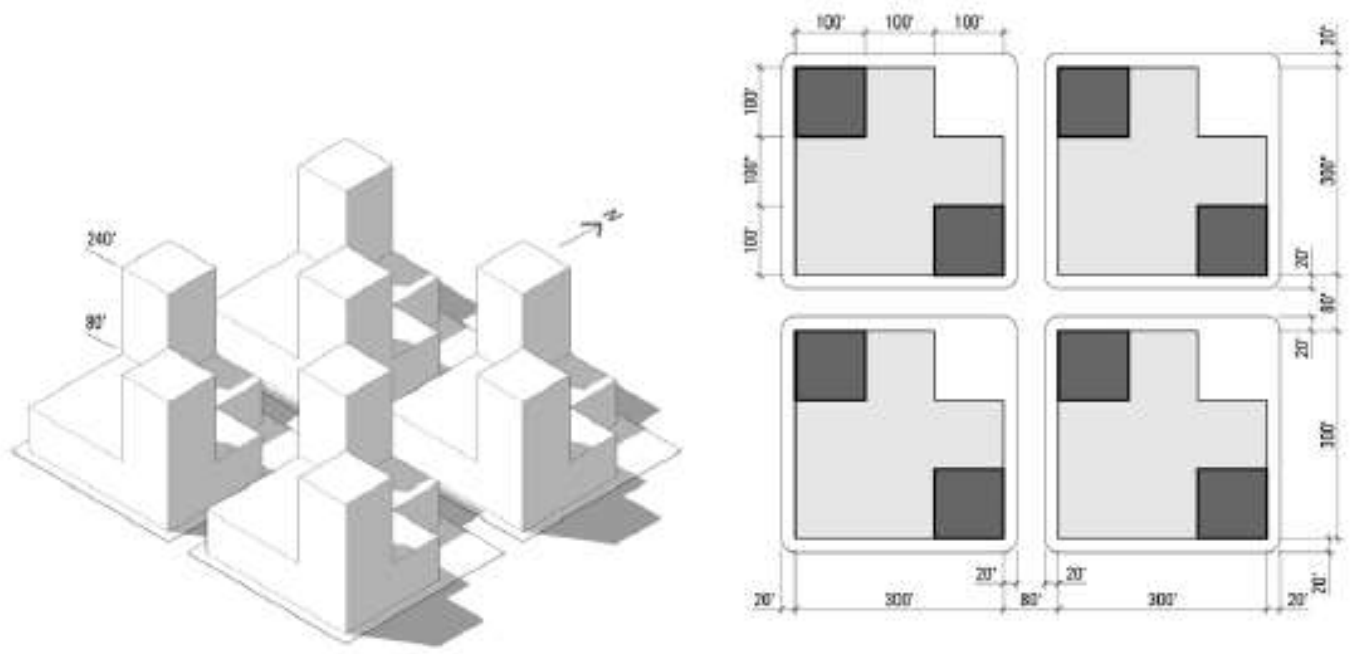

Source: DPP, 2008

The proposed street canyon proportions provide a minimum amount of shading coverage and must be supplemented by additional pedestrian-level shading on different street sides. This could include a double row of trees, single rows, canopies, building overhangs, porticoes, vertical screen walls accented with vines, trees and other plantings. This additional layer of shade shields pedestrians from the reflected 
light and long wave radiation from the structures above, diminishes the amount of heat absorbed by sidewalks, and helps in the mitigation of UHI (DPP, 2008).

\subsubsection{Courtyards}

Another urban element that could be used to balance thermal comfort and UHI is the courtyard. Courtyards can be well closed during daytime to minimize the overall heat absorbed by the urban

Figure (4) Additional shading and courtyards geometry, but then opened during the nighttime to accelerate radiative cooling (Rosenlund, 2000) and encourage natural ventilation (DPP, 2008) (Figure "4"). Courtyards can also be used as heat sinks to store heat through the expansive surface area during daytime in order to benefit from it during the cooler nights (Ratti et al, 2003).In this way, courtyards are moderators the role of which will be determined according to local climate conditions which will differ seasonally and from a desert environment to another.

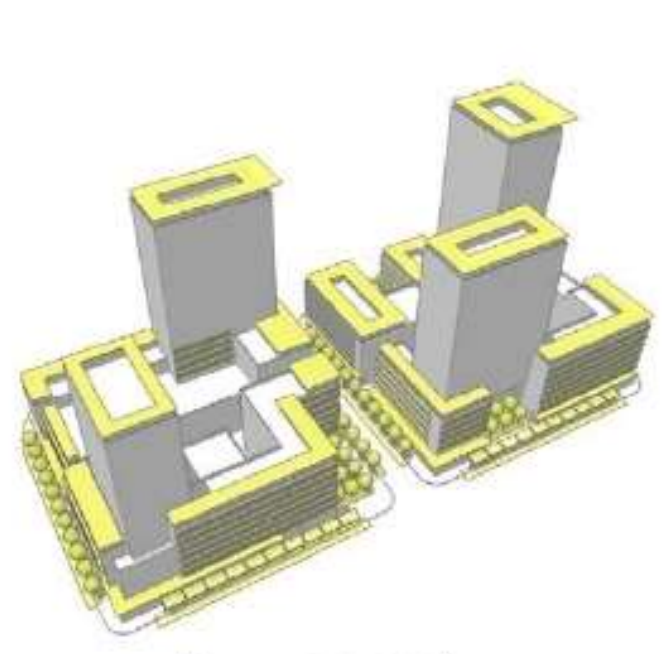

(Source: DPP, 2008)

\subsubsection{Open spaces}

A mesh of open spaces, distributed evenly over the whole urban canopy, is more effective than reliance on a few large ones (Shalaby, 1995). Such a mesh facilitates horizontal exchange of air bodies of varying temperatures especially when enhanced with through-block connectors contributing therefore to the development of the 'Connected Oasis' (DPP, 2008, 4-12). The dimensions of open spaces and courtyards should not be more than three times the surrounding buildings' heights to prevent wind draft (Shalaby, 2004). Within this mesh of open spaces "cool pockets" (areas of concentrated shading and cooling through the urban fabric) could be allocated. These pockets are to utilize the full range of cooling strategies such as shading, low mass materials, evapotranspiration, the presence of water and air movement to reduce the standard effective temperature ${ }^{29}$ on hot summer days. Densely planted plazas also function to cleanse the air in the immediate area of air born pollutants. Cool pockets should also be provided on a micro-planning scale for over exposed areas such as street corners and bus stops (DPP, 2008).

\subsubsection{Size and movement}

The increase in sky view factor and airflow decreases the reliance on air conditioning and hence the demand for electricity, both of which decrease anthropogenic heat generation and, hence further alleviation of UHI. Other means of anthropogenic heat

29 The heat experienced by a person in the urban environment is a combination of air temperature and the heat radiating from surrounding surfaces. Standard effective temperature is the overall temperature felt out of these two sources of heat. 
reduction include promoting more environment- friendly transportation choices such as walking, cycling and public transportation. This could be achieved by promoting small size ${ }^{30}$, self-sustained, self-contained, transit oriented developments with mixed land uses ${ }^{31}$. Small-size developments also mean less UHI intensity.

\subsection{Materials and vegetation}

Simple ways to cool hot arid cities are the use of reflective surfaces (rooftops, walls and pavements), planting of urban vegetation, and introduction of water. These ways can have substantial effect on urban air temperature and hence can reduce energy use and smog formation (Akbari, 2006; Memon et al, 2008), all of which mean less UHI. The following discuss these simple ways in more details.

\subsubsection{Cool and green roofs}

Roofs receive the most solar radiation especially in summer (Rosenlund, 2000) and are held responsible for heating the urban mass, particularly the shallow compact one. A variety of techniques have been used to reduce the amount of heat absorbed by the roof surface. These include high albedo/cool roofs, green roofs and green sky roofs. Each method has its own way of enhancing thermal comfort and alleviating UHI (DPP, 2008).

A high solar reflectance, or albedo, is the most important characteristic of a cool roof as it helps to reflect sunlight and heat away from a building, reducing roof temperatures. A high thermal emittance also plays a role, particularly in climates that are warm and sunny. When exposed to sunlight, a surface with high emittance will reach thermal equilibrium at a lower temperature than a surface with low emittance, because the high-emittance surface gives off its heat more readily (USEPA, 2009d). Together, these properties help roofs to absorb less heat and stay cooler up to $28-33^{\circ} \mathrm{C}$ than conventional materials during peak summer weather (USEPA, 2009g), creating therefore better thermal comfort daytime and lower UHI nighttime. Cool roofs can, also, lower cooling energy use, peak electricity demand, air pollution and greenhouse gas emissions (USEPA, 2011b), which in turn contribute to UHI mitigation.

A green roof, or rooftop garden, is a vegetative layer grown on a rooftop. Green roofs provide shade; remove heat from the air through evapotranspiration, reducing temperatures of the roof surface and the surrounding air; and act as insulators for buildings, reducing energy needed to provide cooling, hence improving thermal comfort and alleviating $\mathrm{UHI}^{32}$. Green roofs can be installed on a wide range of buildings, from industrial facilities to private residences. They can be as simple as a

\footnotetext{
30 A community (or a sub-community in case of a bigger community) with a radius of 450 meters, 5 minutes walking, is a walkable community (Ryn and Calthorpe, 1986).

31 Transit oriented developments with mixed land uses also minimize roads and number of parking lots needed (USEPA, 2009e) which, in turn, means less UHI (Gardiner and Heller, 2008).

${ }^{32}$ On hot summer days, the surface temperature of a green roof can be cooler than the air temperature, whereas the surface of a conventional rooftop can be up to $50^{\circ} \mathrm{C}$ warmer.
} 
2-inch covering of hardy groundcover or as complex as a fully accessible park complete with trees ${ }^{33}$ (USEPA, 2010).

A green sky roof is essentially a trellis supporting vines over an accessible roof surface. They are most effective from a thermal comfort perspective, providing relatively cool temperatures between the surface of the roof and the shaded layer (DPP, 2008), in addition to lowering the amount of heat absorbed by the roof surface.

\subsubsection{Cool pavements}

Conventional dark, thick, dense and impermeable paving materials, which cover nearly $30-45 \%$ of urban areas, can reach peak summertime temperatures of 48 $67^{\circ} \mathrm{C}$, transferring excess heat to the air above them ${ }^{34}$ (USEPA, 2009c). They store a great deal of heat, releasing it into the air during cooler evening hours. Therefore, Heat stored in pavement is one of the major contributors to $\mathrm{UHI}$, the mitigation of which can be achieved by using materials that are brighter, porous and lower in density $^{35}$, called cool pavements (DPP, 2008). These cool pavements reflect more solar energy, enhance water evaporation, and remain cooler than conventional pavements (USEPA, 2009c), helping therefore to directly enhance thermal comfort daytime $^{36}$ and alleviate UHI nighttime. In addition, they contribute to more alleviation of $\mathrm{UHI}$ as they can indirectly help reduce energy consumption, air pollution, and greenhouse gas emissions ${ }^{37}$ (USEPA, 2011b).

\subsubsection{Cool and green walls}

Similar to cool roofs, cool walls are characterized by a high reflectivity to short wave radiation and high emissivity to long wave radiation. Thin, smooth and light colored cladding systems perform well in overheated environments if they are applied over a free flowing air space, allowing excess heat to be released into the atmosphere rather than conducting through the wall to the building interior. These light mass cool walls are appropriate for use on towers above the street wall cavity. Yet, when

${ }^{33}$ Green roofs have become popular in the United States. Roughly 8.5 million square feet installed as of June 2008 (USEPA, 2010). In Egypt, since its introduction in 1999 by the United Nations' Food and Agriculture Organization, between 5,000-6,000 square meters of roof areas have been greened (Maged, 2008).

${ }^{34}$ They also heat up stormwater as it runs off the pavement into local waterways (USEPA, 2009c).

${ }^{35}$ Less dense pavements can be reached by adding recycled crumb rubber as an aggregate in asphalt and concrete. Rubber is relatively low in density and is a poor conductor of heat resulting in lower surface temperatures during the day and less total heat stored during the evening hours (DPP, 2008).

${ }^{36} \mathrm{Cool}$ pavements in parking lots and areas where people congregate or children play provide a more comfortable environment (USEPA, 2009c).

${ }^{37} \mathrm{Cool}$ pavements have other positive impacts on the environment. They can help lower the temperature of runoff, resulting in less thermal shock to aquatic life in the waterways into which stormwater drains. Permeable roadway pavements can improve safety by reducing water spray from moving vehicles and increasing traction through better water drainage. In addition, the open pores of permeable pavements can reduce tire noise by two to eight decibels and keep noise levels below 75 decibels, although noise reduction may decline over time. Reflective pavements can enhance visibility at night, potentially reducing lighting requirements and saving both money and energy (USEPA, 2009c). 
shaded from the sun in base blocks, high mass walls will maintain a relatively low temperature and, if located near the pedestrian zone, will result in lower radiant and air temperatures (DPP, 2008), hence enhancing thermal comfort daytime in the street canyon. Green walls such as wall-climbing vines can also be used for shading and induce cooling through evapotranspiration (DPP, 2008) and chimney effect.

\subsubsection{Plantation and water}

Research has shown that planting and vegetation, one of the most widely applied UHI mitigation measure (Memon et al, 2008), is a simple and effective way to reduce UHIs (US EPA, trees and vegetation).

In relation to lowering temperature, several studies have indicated a strong correlation between decrease in temperature and the presence of green areas and trees (Wong and Yu, 2005; Song, 2005). Trees and vegetation lower surface and air temperature by providing shade and through evapotranspiration (Endreny, 2008; USEPA, 2009f; USEPA, 2009e) ${ }^{38}$. Trees and vegetation are most useful as a mitigation strategy when planted in strategic locations around buildings or to shade pavement in parking lots and on streets. Planting deciduous trees or vines to the west is typically most effective for cooling a building, especially if they shade windows and part of the building's roof (USEPA, 2009f). Largely deciduous, drought-resistant and fruit-bearing trees are recommended for hot arid environments (Pearlmutter, 2000). Yet, whenever possible, introducing water into arid cities through artificial lakes and ponds, and fountains is useful day and night.

In relation to lowering air pollution, plants and vegetation can filter dust through dry deposition; absorb and dilute pollutants such as ozone, carbon dioxide and sulpher dioxide (Pherson, 2011; USEPA, 2009f) and collects heavy metals such as cadmium and lead. And, in relation to wind control, tree shelters may reduce wind by $50 \%$ extending 10 to 15 times the height of the trees on the lee side.

\section{CONCLUISONS AND FUTURE RESEARCH}

This theoretical study summarizes Urban Heat Island significance, types and characteristics; presents how it is generated; and discusses its generating factors. The literature reviewed identifies urban geometry and materials thermal characteristics as the most influential factors in determining the UHI effect. In hot arid regions, to which a significant portion of the Arab world belongs, these two factors play a bigger role due to intense solar radiation.

In response, this paper constructs a conceptual framework of UHI mitigation tools relevant to hot arid environments from dispersed literature available. This novel construct stands as the contribution of this study. The construct includes two groups of interventions. The first group is to only be observed in the urban design and

${ }^{38}$ Shaded surfaces, for example, may be $11-25^{\circ} \mathrm{C}$ cooler than the peak temperatures of unshaded materials. Evapotranspiration, alone or in combination with shading, can help reduce peak summer temperatures by $1-5^{\circ} \mathrm{C}$ (USEPA, 2009f). 
planning stage and deals with urban form characteristics. The second could be applied on an existing urban development and deals with the introduction of cool materials, plantation and water.

A smart contemporary compact urban geometry, as coined in this paper, would theoretically balance between achieving thermal comfort daytime and alleviating UHI by:

1. orienting street canyons to north-south; and applying 1:3 and $1: 2$ proportions to north-south and west-east street canyons respectively to provide shade while maximizing sky view factor nighttime;

2. creating cold corridors through directing street canyons to preferable wind directions with an ideal height to width proportion of 1.54 ;

3. enhancing air turbulence by removing significant portions of street wall volume and placing towers diagonally at the corners of blocks (in the case of high-rise districts);

4. providing an additional layer of pedestrian-level shading to protect pedestrians and sidewalks from short-wave and long-wave radiation;

5. creating a connected oasis of courtyards and open spaces to moderate temperature and enhance airflow and cross ventilation;

6. being (or being broken into sub-communities) small in size, self contained, self sustained, transit oriented with mixed land uses to discourage car-based designs and plans;

7. applying cool roofs, pavements and walls; and introducing plantation wherever possible.

However, it has to be clearly stated that this conceptual framework, due to its very nature - being a collect of mosaics, is not applicable to any specific desert environment. Further research is needed to verify, contextualize and complete this framework, turning it into possible urban design parameters applicable to a certain locality/climatic zone.

Possible future research avenues, therefore, include but not limited to the following, regarding UHI mitigation in a specific desert geographical location:

1. Nature and degree of urban compactness and roughness

2. Street canyons orientations and proportions in relation to solar radiation and wind.

3. Courtyards and open spaces network and proportions

4. Self sustained, self contained communities

5. Mixed land use planning

6. Innovative transit modes

\section{References}

Akbari, H. (2006). Energy Saving Potentials and Air Quality Benefits of Urban Heat Island Mitigation. Lawrence Berkeley National Laboratory: Lawrence Berkeley National Laboratory. LBNL Paper LBNL-58285, [online] available at:

http://escholarship.org/uc/item/4qs5f42s (accessed 25 April 2011) 
Bottayan, Z., Kircsi, A., Szegedi, S. and Unger, J. (2005). The Relationship Between Built-Up Areas and The Spatial Development of The Mean Maximum Urban Heat Island In Debrecen, Hungary. International Journal of Climatology 25, 405-418.

Chen, X., Zhao, H., Li, P. and Yin, Z. (2006). Remote Sensing Image-based Analysis of the Relationship between Urban Heat Island and Land Use/Cover Changes. Remote Sensing of Environment 104, 133-146.

Dicitionary.com (2011). Dictionary [online] available at: http://dictionary.reference.com/browse/evapotranspiration (accessed at 5-4-2011).

DPP (Downtown Phoenix Plan) (2008). Sustainable Development in a Desert Climate, [online] available at http://www.phoenix.gov/urbanformproject/dtplan04.pdf (accessed 25 April 2011).

Endreny, T. (2008). Naturalizing Urban Watershed Hydrology to Mitigate Urban Heat Island Effects. Hydrological Processes 22, 461-463.

Gardiner, K. and Heller, A. (2008). Green Design at Any Size - Urban Heat Island Effect \& TOD, [online] available at: http://www.railvolution.com/rv2008 pdfs/rv2008 139d.pdf (accessed 26 April 2011).

Golden, j. (2004). The Built Environment Induced Urban Heat Island Effect in Rapidly Urbanizing Arid Regions - A Sustainable Urban Engineering Complexity. Environmental Sciences 1 (4), 321-249.

Guhathakurta, S. and Gober, P. (2007). The Impact of the Phoenix Urban Heat Island on Residential Water Use. Journal of the American Planning Association 73 (3), 317-329.

Hedquist, B., Brazel, A., Di Sabatino, S., Carter, W. and Fernando, H. (2009). Phoenix Urban Heat Island Experiment: Micrometeorological Aspects. Eighth Symposium on the Urban Environment, Timothy R. Oke Symposium 10-15 January, 2009, [online] available at: http://ams.confex.com/ams/89annual/techprogram/paper_145712.htm (accessed 25 April 2011).

IRIN (2011). AfRICA: The Special Case of Mega-Cities, [Online] available at: http://www.irinnews.org/Report.aspx?Reportld =62448 (accessed 25 April 2011).

Jusuf, S., Wong, N., Hagen, E., Anggoro, R. and Hong,Y. (2007) The Influence of Land Use on the Urban Heat Island In Singapore. Habitat International 31, 232-242.

Kato, S. and Yamaguchi, Y. (2005). Analysis of Urban Heat Island Effect Using ASTER and ETM+ Data: Separation of Anthropogenic Heat Discharge and Natural Heat Radiation Sensible Heat Flux. Remote Sensing of Environment 99, 44-54.

Kolokotroni, M. and Giridharan, R. (2008). Urban Heat Island Intensity in London: An Investigation of the Impact of Physical Characteristics on Changes in Outdoor Air Temperature during Summer. Solar Energy 80, 986-998.

Maged, A. (2008). Green Valleys Grace Cairo's Rooftops, in Daily News Egypt, [online] available at: http://www.dailystaregypt.com/article.aspx?ArticlelD=18694 (accessed 25 April 2011).

Memon, R., Leung, D. and Chunho, L. (2008). A Review on the Generation, Determination and Mitigation of Urban Heat Island. Journal of Environmental Sciences 20, 120-128.

NASA (2002). NASA Satellite Confirms Urban Heat Islands Increase Rainfall around Cities. Science Daily, [online] available at: http://www.sciencedaily.com/release/2002/06/020619074019.htm (accessed 25 April 2011). 
Ooka, R. (2007). Recent Development of Assessment Tools for Urban Climate and Heat Island Investigation Especially Based on Experience in Japan. International Journal of Climatology 27, 1919-1930.

Pearlmutter, D. (2000). Patterns of Sustainability in Desert Architecture. Arid Lands Newsletter 47, 1-12, [online] available at: http://ag.arizona.edu/oals/ALN/aln47/pearlmutter.html (accessed 25 April 2011).

Pherson, G. (2011). The Impact of Shade Trees on Reducing Heat Island Effect in Parking Lots, [online] available at: http://aridzonetrees.com/AZT Guest Articles/Impact of Shade Trees on Reducing Heat Island Effect in Parking Lots.htm (accessed 25 APRIL 2011).

Ratti, C., Raydan, D. and Steemers, K. (2003). Building Form and Environmental Performance: Archetypes, Analysis and an Arid Climate. Energy and Buildings 35, 49-59.

Rosenlund, H. (2000). Climatic Design of Buildings using Passive Techniques. Building Issues $10(1), 3-26$.

Ryn, S and Calthorpe, P (1986). Sustainable Communities, a New Design Synthesis for Cities, Suburbs and Towns. San Francisco, Sierra Club Books.

Sarrat, C., Lemonsu, A., Masson, V. and Guedalia, D. (2006). Impact of Urban Heat Island on Regional Atmospheric Pollution. Atmospheric Environment 40, 1743-1758.

Shalaby, A (1995). Human Settlements and Sustainable Development: A Model of Environmentally Adapted Site Selection and Urban Form Design Principles for Establishing Sustainable Desert Settlements. M.Sc. thesis, Ann Arbor, UMI Dissertation Services.

Shalaby, A (2004.) Compact Urban Form: A sustainable Urban Form in Desert Environments. The 2004 First Conference, Sustainable Architectural and Urban Development, Department of Architecture, Cairo University, Cairo 24-26 February 2004.

Song, Y. (2005). Influence of New Town Development on the Urban Heat Island - The Case of the Bundang Area. Journal of Environmental Sciences 17 (4), 641-645.

Souza, L., Rodrigues, D. and Mendes, J. (2003). Sky View Factors Estimation Using a 3D-GIS Extension. Eighth International IBPSA Conference, Eindhoven, Netherlands, August 11$14,2003$.

Stone, B. and Norman, J. (2006). Land Use Planning and Surface Heat Island Formation: A Parcel-based Radiation Flux Approach. Atmospheric Environment 40, 3561-3573.

USEPA (2009a). Air Quality, [Online] available at: http://www.epa.gov/region4/airqualitytoolkit/3_sources/landuseurbandesignaffectai rquality.pdf (accessed 25 April 2011).

USEPA (2009b). Basic Information, [online] available at: http://www.epa.gov/heatisland/about/index.htm (accessed 25 April 2011).

USEPA (2009c). Cool Pavements, [online] available at: http://www.epa.gov/heatisland/mitigation/pavements.htm (accessed 25 April 2011).

USEPA (2009d). Reducing Urban Heat Islands: Compendium of Strategies, [online] available at: http://www.epa.gov/heatisld/resources/compendium.htm (accessed 25 April 2011). 
USEPA (2009e). Smart Growth and Urban Heat Islands, [online] available at: http://www.epa.gov/heatisld/resources/pdf/smartgrowthheatislands.pdf (accessed 25 April 2011).

USEPA (2009f). Trees and Vegetation, [online] available at: http://www.epa.gov/heatisland/mitigation/trees.htm (accessed 25 April 2011).

USEPA (2009g). Cool Roofs, [online] available at: http://www.epa.gov/heatisland/mitigation/coolroofs.htm (accessed 25 April 2011).

USEPA (2010) Green Roofs, [online] available at: http://www.epa.gov/heatisland/mitigation/greenroofs.htm (accessed 25 April 2011).

USEPA (2011a) Heat Island Impacts, [online] available at: http://www.epa.gov/heatisld/impacts/index.htm (accessed 25 April 2011).

USEPA (2011b) Urban Heat Island Mitigation, [online] available at: http://www.epa.gov/heatisld/mitigation/index.htm (accessed 25 April 2011).

Vasishth, A. (2006). An Integrative Ecosystem Approach to a More Sustainable Urban Ecology: Heat Island Mitigation, Urban Forestry, and Landscape Management Can Reduce the Ecological Footprint of Our Cities. The Association of the Collegiate Schools of Planning $47^{\text {th }}$ Annual Conference, November 9-12, Fort Worth, Texas.

Wikipedia, the Free Encyclopedia (2009). Urban Heat Island, [online] available at: http://en.wikipedia.org/wiki/Urban heat island (accessed 8 March 2009).

Wilby, R. (2007) Consulting Climate Change Scenarios of Urban Heat Island Intensity and Air Quality. Environment and Planning B: Planning and Design 35, 902-919.

Wong, N. and Yu, C. (2005) Study of Green Areas and Urban Heat Island in a Tropical City. Habitat International 29, 547-558. 